\title{
GESONDHEIDSVOORLIGTING BY SWANGER VROUE
}

\author{
M.E. Bester
}

\section{Opsomming}

Die verskaffing van gesondheidsvoorligting en -inligting aan die swanger vrou, behoort hoë prioriteit te geniet, ongeag die gebrek aan betroubare meetinstrumente on die effektiwiteit daarvan te evalueer en die gebrek aan gewaarborgde resultate.

Ondersoek is tydens navorsing vir 'n Magisterverhandeling in Verpleegkunde ingestel na primigravidas wat die haërisiko klinieke by die Tygerberghospitaal bygewoon het, en hul kennis en houding teenoor belangrike aspekte wat tydens swangerskap aandag behoort te geniet.

Onderhoude is met pasiënte gevoer rakende aspekte soos gesinsbeplanning, borsvoeding, rook en gevaartekens wat tydens swangerskap kan voorkom. Dit het geblyk dat woorligting oor rook en alkohol baie min impak gehad het. Meer pasiënte was positief oor borsvoeding en gesinsbeplanning nadat hulle voorligting daaromtrent ontvang het. Bevindinge war kommerwekkend was, was die feit dat pasiënte se kennis oor gevaartekens tydens swangerskap minimaal was. Pasiènte het ook nie begrip rakende die redes waarom die verskillende toetse en ondersoeke gedoen word gehad het nie. Dit het skynbaar nie 'n negatiewe effek op kliniekbywoning geliad nie.

Die verpleegkundige het nie 'n prominente rol gespeel to.v. die verskaffing van voorligting en inligting nie en die pasiënte het 'n geneesheer bo ' $n$ verpleegkundige verkies om die nodige inligting te verskaf. Dit word aanbeveel dat meer krities gekyk moet word na die wyse waarop voorligting by die klinieke aangebied word, sowel as die inhoud van die worligting. Voorligting moet ooreenstem met die behoeftes, kennis en opvoedkundige vlak van die pasiënt en prioriteite vir voorligting moet bepaal word Sekere noodsaaklike inligting soos die gevaartekens moet met elke besoek herhaal word en die pasiënt se kennis moet woortdurend evalueer word. Verpleegkundiges se vaardigheid om voorligting te gee, moet nie net uitgebrei word nie, maar dit moet ook geèvalueer word.

\section{Summary}

Health educution and information in pregnancy must be a priority, despite the lack of instruments to evaluate the effectiveness of the education and the fact that positive results can not be guaranteed.

During research done for a Masters degree on the utilization of antenatal services by high risk primigravidae at the Tygerberg hospital, patients were interviewed on various aspects that are important during pregnancy, like family planning, breastfeeding, smoking and danger signs that may occur during pregnancy.

It was found that education on smoking and alcohol had little intpact. However, more patients felt positive about breastfeeding and family planning after they received information about it. A disturbing finding was that parients had very little knowledge about the danger signs that may occur during pregnancy. They did not know the reasons for the examinations and tests performed during pregnancy, although it probably had no negative effect on the attendance of the antenatal clinics.

Most of the patients preferred a doctor rather than a nurse to give education and information. It is recommended that health education be looked at critically to ensure that it satisfies the needs of the patients and that the patients' pre-existing knowledge and their educational abilities are taken into consideration. Essential knowledge like the danger signs must be repeated at every visit and the patient's comprchension of it, must be evaluated. It is further not only important to extend the knowledge of nurses on health education, but also to evaluate their competence in giving health education.

\section{INLEIIING}

Gesondheidsvoorligting is 'n noodsalaklike en integrale komponent van primère gesondheidsorgdienste. Voorligting en inligting is egter nie ' $n$ waarborg dat positicwe veranderinge in 'n individu so gesondheidsgedrag en -leefstyl plaasgevind het nie, aangesien sodanige veranderinge impliseer dat daar ' $n$ verandering in dic individu se waardes en houdings moet plaasvind. Waardes en houdings is egier so inherent deel van 'n individu, dat veranderinge mocilik geinternaliseer kan word.

Alhoewel positiewe veranderinge nic noodwendig voortvloei uit voorligting nie, is inligting egter 'n noodsaaklike voorvereiste vir enige veranderinge om te kan plaasvind.
Dit bly altyd problematies om te evalueer of voorligting die gewenste veranderinge in dic lewenspatroon van die individu tot gevolg het, en indien die veranderinge wel plaasvind, of dit die gewenste uitwerking op die individu se gesondheid het.

Nictecnstaande die gebrek aan betroubare mectinstrumente en gewaarborgde resultate, is 
daar in die literatuur baie bewyse dat voorligting tydens swangerskap van besondere waarde is.

Eggertsen en Benedetti (1987:327) het bewys dat vroeè geneeskundige hulp en mediese ingryping by 'n pasiënt met verminderde fetale bewegings, intra-uteriene dood kan verminder.

Wiles (1984:257) het weer gevind dat primigravidas wie voorligting oor borsvoeding gehad het, meer suksesvol in borsvoeding was as diegene wat geen voorligting ontvang het nie.

Die effektiwiteit van voorligting tydens swangerskap word egter gekompliseer omdat van die gewensde veranderinge soos staking van rook- en alkoholgebruik eintlik reeds voor swangerskap behoort plaas te vind, ten einde optimale voordele vir die ongebore fetus in te hou.

\section{DOEL VAN DIE NAVORSING}

In 'n ondersoek van 50 primigravidas wat die hoërisiko-klinieke by die Tygerberghospitaal bygewoon het, is ondersock onder meer na die volgende aspekte ingesicl:

1. Die pasiënte se kennis, houding en die gebruik van sigarette, alkohol en 'n gesonde dieet;

2. Die pasiènte se houding leenoor borsvoeding en gesinsbeplanning;

3. Die pasiènte se kennis omtrent die gevaartekens van swangerskap;

4. Die gebruik van medikasie;

5. Die pasiënte se kennis omtrent die redes vir voorgeboorte-toetse en -ondersoeke;

6. Die persoon(e) van wie die pasiënte die meeste inligting ontvang het.

\section{LITERATUURSTUDIE}

Sekere aspekte van die literatuurstudie gaan vervolgens uitgelig word ten einde die bevindinge van die navorser te beklemtoon en te staaf.

Volgens Chaisson (1979:1-2) is dit die plig van alle gesondheidspersoneel om persone te motiveer tot 'n gesonde leefstyl deur akkurate, wetenskaplike inligting te voorsien. Ten spyte van bepcrkinge soos gebrekkige fondse, die feit dat die uitkoms of resultate moeilik of selfs glad nie meetbaar is nie, en dat individu se omstandighede ongunstig is om die gewensde veranderinge te implementeer, is dit noodsaaklik om vol te hou met voorligtingsprogramme. (Having a baby in Europe, 1985:83).

Dit blyk uit verskeie studies wat onderneem is dat pasiente oor die nodige kennis t.o.v. die gevare van rook tydens swangerskap, en die voordele van 'n gesonde dieet beskik, maar min pasiênte het geweet dat alkohol skadelik is. Ten spyte daarvan het baie min vroue se gebruik hieromtrent verander. In die studie van Dowsett (1985:83-86) kon 146 uit 206 vroue advies oor rook herroep. Slegs 18 van die vroue het egter ophou rook, terwy! 31 vroue minder gerook het en dit ten spyte van die vroue se kennis oor die negatiewe gevolge wat rook op die ongebore fetus se groei het. Daarenteen het MacArthur, Newton en Knox (1987:299), in hulle studie gevind dat daar wel veranderinge in die vrouens se rookgewoonte was.

Dieetaanpassings is volgens Eiser en Eiser (1985:55), veral ten opsigte van melk, vrugte en proteine gemaak nadat hulle voorligting daaroor ontvang het.

Ontstellend min vroue het volgens Eiser en Eiser (1985:56) geweet dat al kohol skadelik vir die ontwikkelende fetus was.

Eiser en Eiser (1985:57) het gevind dat die meeste pasiènte net 'n vae begrip gehad het oor die redes vir voorgeboorte-ondersoeke en -loetse. In die studies van Eiser \& Eiser (1985:58) het dit verder geblyk dat die verpleegkundige ' $n$ minder belangrike rol ten opsigte van voorligting gespeel het in vergelyking met die geneesheer; familie en vriende. Tilley, Gregor en Thiessen (1987:296), het trouens gevind dat pasiènte 'n geneesheer bo ' $n$ verpleegkundige verkies het om voorligting te verskaf Volgens Margen en Griffith (in Ferrans, Powers \& Kasch, 1987:372), word die verpleegkundige nie altyd as 'n onafhanklike praktisyn gesien nie, maar as"...ancilliary to the physician". Conway-Rutkowski (1982:459), beweer dat die rede vir bogenoemde verskynsel is dat "...nurses fail to become sensitive to the patient's perceptions of his needs."

\section{METODE}

'n Beskrywende opname-studie is gedoen nadat 'n deeglike literatuurstudie van plaaslike en internasionale literatuur onderneem is, wat dan ook as die teoretiese vertrekpunt gedien het vir die vraelys wat opgestel is.

Tydens 1988 en 1989 is onderhoude aan die hand van gestruktureerde vraelyste met die pasiënte gevoer. Die pasiènte is ewekansig gekies (elke vyfde pasiënt wie by die kliniek aangemeld het) om aan die projek deel te neem. Deelname was vrywillig en met die voorwarde dat die pasiënt enige tyd tydens die onderhoud aan die navorsing kon onttrek.

Verskeie vrae rondom bepaalde aspekte rakende die benutting van voorgeboortesorgdienste is gestel. Die pasiënte is opgevolg ten opsigte van die tipe bevalling, massa en Apgartelling van die baba ten einde die uitkoms van die swangerskap te ondersoek vir enige moontlike verband tussen die uitkoms van die swangerskap en enige van die aspekte wat nagevors is. Al die pasiënte het eers die gemeenskapsklinieke bygewoon alvorens hulle weens 'n risikofaktor na die hospitaal-kliniekc verwys is.

\section{BEVINDINGE}

\section{Biografiese Besonderhede}

Al die pasiënte was 28 weke en langer swanget. Twee-en-dertig (64\%) van die pasiènte was tussen 17 en 20 jaar oud en 48 (96\%) van die pasiènte was ongetroud. Van die pasiènte het slegs $50 \%$ (25 pasiènte) laerskoolopleiding gehad, $18(36 \%)$ van die pasiènte was werkJoos en $48 \%$ van die pasiënte het ongeskoolde arbeid verrig. Twee-en-dertig van die pasiente $(64 \%)$ se inkomste was R.300 of minder per maand.

\section{Rookgewoonte}

Alhoewel die meerderheid van die pasiente $(82 \%)$ geweet het dat rook skadelik is vir die

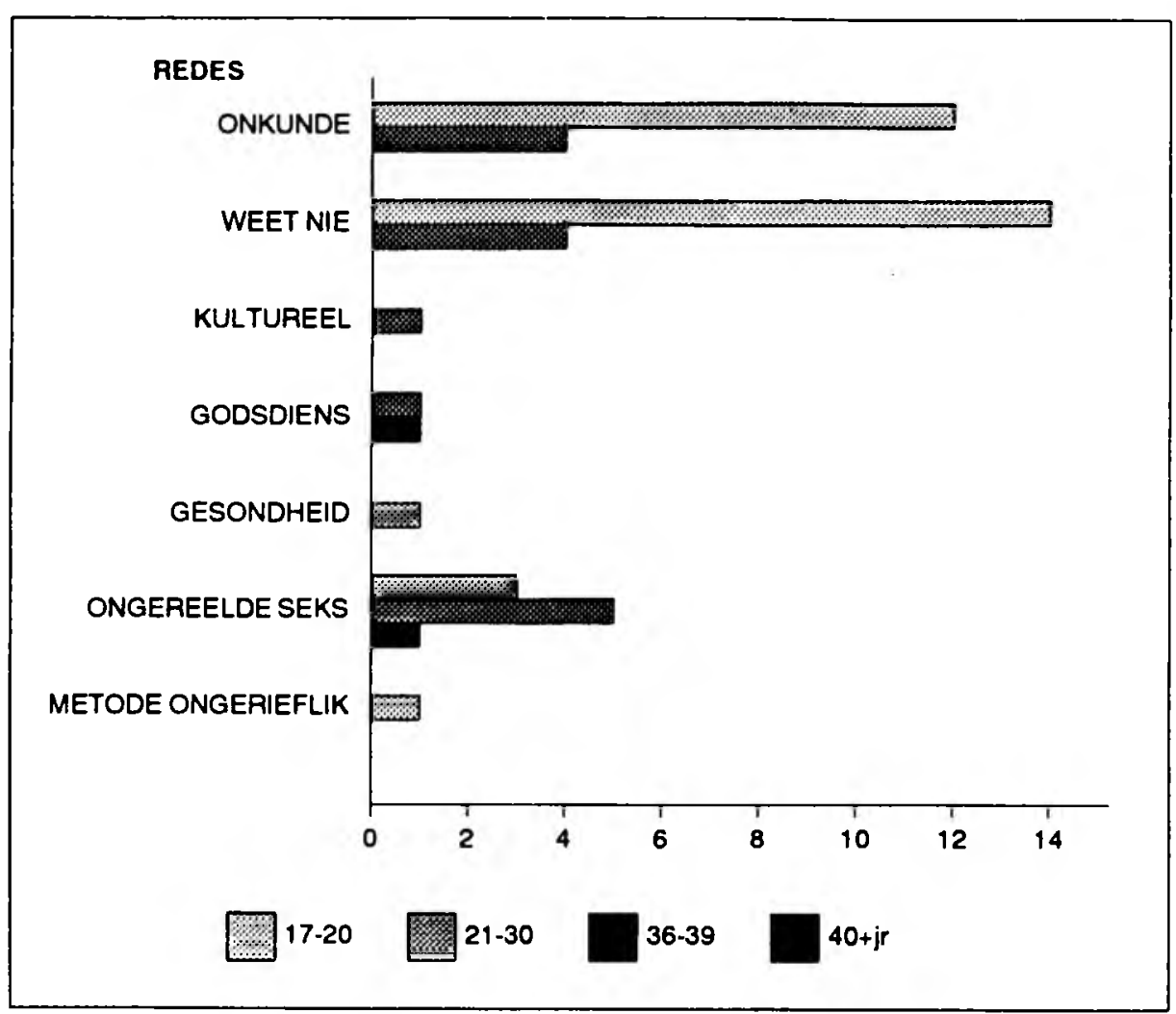

Figuur 1

Pedes vir Gesinsbeplanning nie gebrulk

$(\mathrm{N}=48)$ 


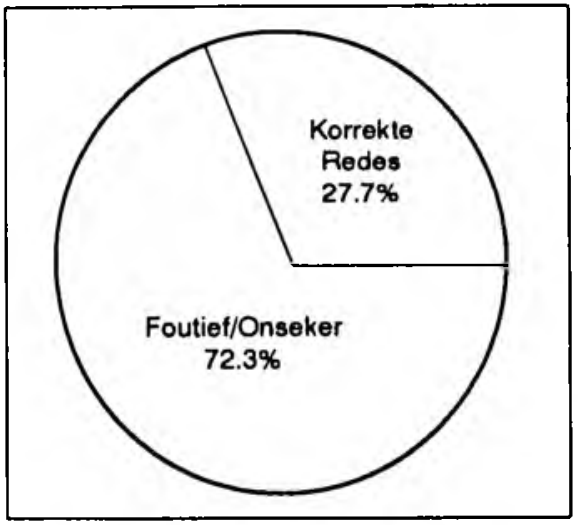

Figuur 2

Redes vir gebrulk van Ystertablette $(n=47)$

respondente wel kennis gedra het dat alkohol skadelik vir die ongebore baba is.

\section{Gesinsleeplanning}

Slegs 2 van die respondente het gesinsbeplanning gebruik. Daar is geen beduidende verband gevind lussen die ouderdom van die respondente en of hulle gesinsbeplanning gebruik het nie. Daarenteen is ' $n$ beduidende verband gevind tussen die ouderdom van die respondente en die rede(s) waarom hulle nie gesinsbeplanning gebruik het nie. $(p=0,005)$. Meer respondente in die ouderdomsgrocp 17 tot 20 jaar het redes soos "onkunde" (12 respondente) en "weet nie" (14 respondente) aangegee as die respondente in die ander ouderdomsgroepe. (kyk figuur 1 ).

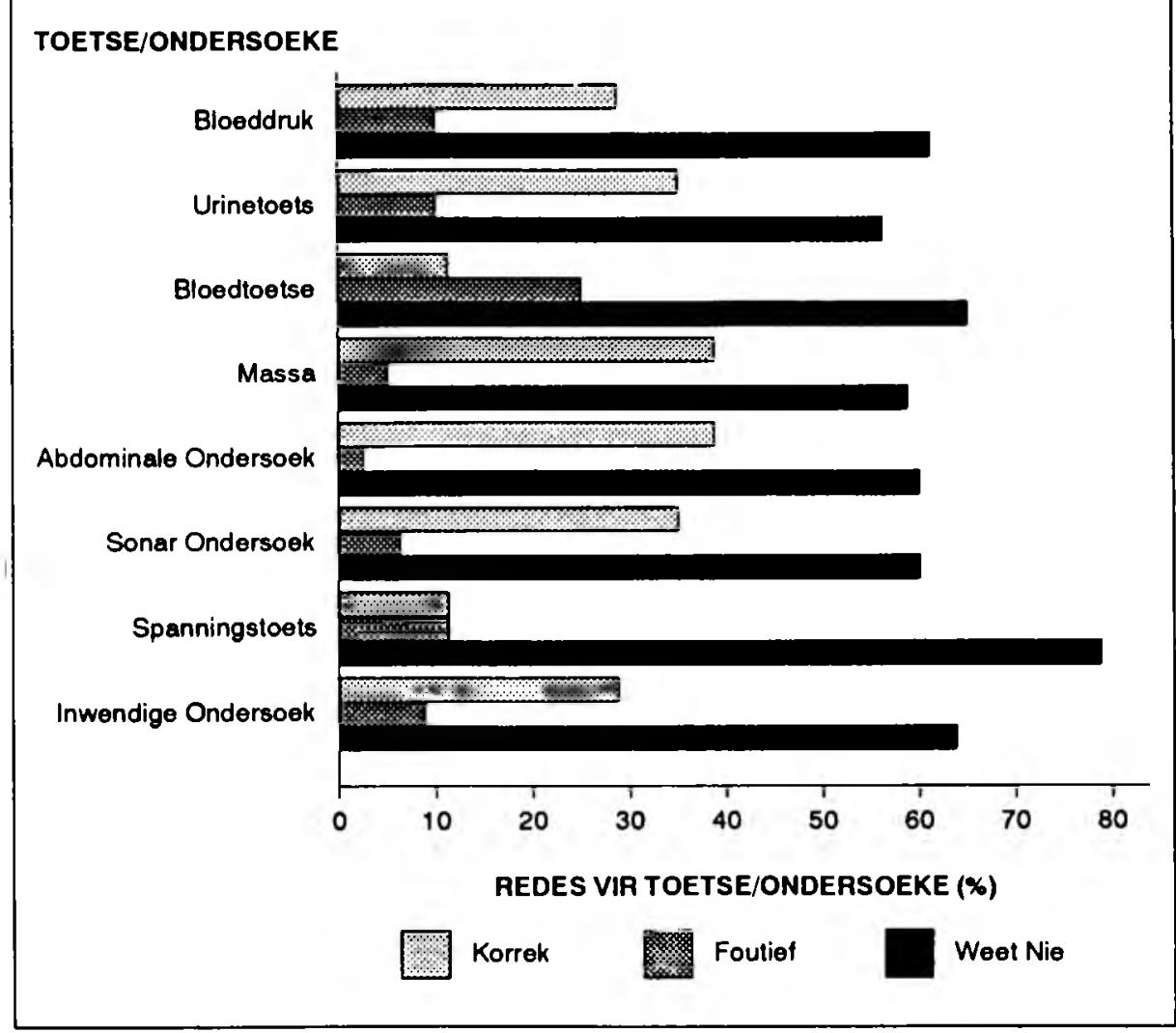

Figuur 3

Kennis van toetse en ondersoeke moeder en baba se gesondheid, het $19(38 \%)$ van die pasiënte wel tot en met dic onderhoud gerook. Geen pasiënt wat gerook het, was van plan om op te hou met rook nie, en dit is interessant om daarop te let dat agt van die 10 het met rook, dit reeds voor swangerskapsduur gedoen het, met ander woorde voordat hulle die voorgeboortekliniek besoek het. Voorligting gegee by die klinick het dus min impak op die besluit gehad om op te hou rook. Dit is belangrik om te besef dat van die respondente se inligting nie altyd noodwendig akkuraat was nie, soos wat in vorige studies ook gevind is.

\section{Alkoholverbruik}

Aangesien slegs 2 van die respondente aangetoon het dat hulle alkohol gebruik, sal nie verder hierop kommentaar gelewer word nic, behalwe om te noem dat $33(66 \%)$ van die respondente wie tydens swangerskap opgehou

Curationis, Vol. 15, No. 2, 1992 pasiente omtrent die redes vir die medikasie, word in figuur 2 gegee.
Borsvoeding

Agt-en-twintig (56\%) van die respondente het op die stadium van die onderhoud reeds voorligting ten opsigte van borsvoeding ontvang. Ten spyte daarvan, het $43(86 \%)$ van die pasiénte te kenne gegee dat hulle beplan het om te borsvoed, omdat dit vir die baba gesonder is. 'n Duidelike verband is aangetoon $(p=0,0341)$ tussen voorligting ontvang oor borsvoeding en die besluit om te borsvoed. Meer van die pasiënte was gemotiveerd om te borsvoed nadat hulle voorligting ontvang het.

\section{Redes vir Toetse en Ondersoeke}

Alhocwel die respondente baie gebrekkige kennis van voorgeboortetoctse en ondersoeke gehad het, het dit skynbaar geen negatiewe effek op hulle kliniekbywoning gehad nie. (kyk figuur 3 vir kennis)

\section{Gevaurtekens tydens Swangerskap}

Drie-en-dertig van die respondente $(66 \%)$ het 'n pamflet ontvang waarop die gevaartekens van swangerskap verskyn. Slegs 11 van hierdie respondente $(33 \%)$ kon onthou dat die verpleegkundige of geneesheer dit met hulle bespreek het. (Sien figuur 4 vir kennis van gevaartekens). Dit is sorgwekkend dat 28 $(56 \%)$ van die pasiënte nie geweet het of onseker was omtrent die korrekte aantal fetale bewegings en die betekenis daarvan.

\section{GEVOLGTREKKINGS}

In hierdie navorsing is soortgelyke bevindinge gemaak as in vorige navorsing omtrent die waarde van advies oor rook en alkohol tydens swangerskap, naamlik dat dit geen of beperkte waarde inhou. Nogtans is die navorser van mening dat daarmee voortgegaan moet word, omdat die moontlikheid bestaan dat die inligting aan ander corgedra kan word, of dat dit miskien met die volgende swangerskap van die pasiënt van waarde kan wees. Die navorser bevraagteken die korrektheid van die sigaret-, maar veral alkoholgebruik soos wat deur die respondente gegee is. Ten spyte van die nie-veroordelende houding van die navorser, kan dit moontlik wees dat die respondente wel bewus was van die gevare van rook en weens skuldgevoelens nie die korrekte inligting weergegee het nie, 'n soortgelyke bevinding as wat Terris (1969:360) en Hamilton et al (1987:30) gemaak het.

Voorligting ten opsigte van gesinsbeplanning was beslis suksesvol in die mate dat dit 'n positiewe ingesteldheid by die pasiènt teweeggebring het. Dit is egter nie moontlik om te voorspel of hierdie houdingsverandering blywend gaan wees al dan nie. Die bevindings ten opsigte van die invloed van voorligting omtrent borsvoeding op die besluit om te borsvoed, was ook positief in so ver die vroue aangedui het dat hulle meer daarop ingestel was om die babas te borsvoed. Dit sou interessant gewees het om te weet hoeveel van die moeders wel by hulle besluit gehou het.

Baie min pasiënte het geweet waarom al die toetse en ondersoeke gedoen word en wat die bevindinge daarvan was (kyk figuur 3 ). Alhoewcl dit skynbaar nie 'n negatiewe effek op kliniekbywoning gehad het nie, het dit tog 'n beduidende verband getoon met die tevredenheid met die diens. Dit is ook 


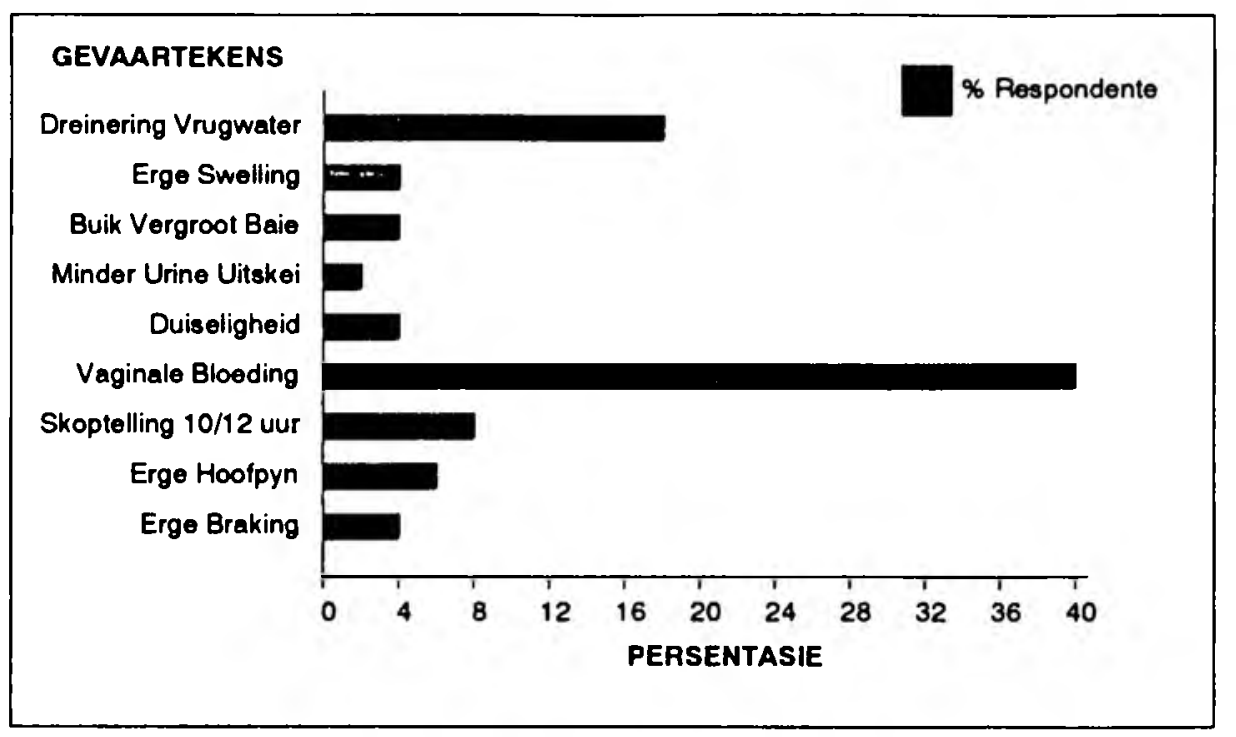

Figuur 4

Kennls van Gevaartekens

insiggewend dat die pasiënt inligting en verduidelikings van die geneesheer eerder as van die verpleegkundige ontvang het en dat pasiënte meer tevrede was met die geneesheer $(p=0,0042)$ as met die verpleegkundige $(p=0,01)$. Dit het uit hierdie navorsing geblyk dat die pasiënte nie alıyd as aktiewe deelnemers aan die bevordering van hulle eie gesondheid en die van hulle ongebore babas gesien is nie. Dic navorser is bewus van beperkinge soos te min tyd en beperkte begripsvermoë van sommige pasiènte, maar is tog van mening dat die pasiënt die reg het om die redes en bevindinge te weet van toetse wat op haar uitgevoer is. Aktiewe betrokkenheid by gesondheid is ook een van die vereistes van primêre gesondheid.

Dit is kommerwekkend dat minder as $20 \%$ van die respondente die gevaartekens, met die uitsondering van vaginale bloeding, kon opnoem (kyk figuur 4). Dit kon moonilik gewees het dat hulle ietwat ongeërg was en nie gedink het dat dit met hulle kon gebeur nie. 'n Ander verklaring kan wees dat 'n pamflet met die gevaartekens wat vir alle pasiënte gegee word, ongeveer met net die helfte van die pasiënte wat dit ontvang het, bespreek is. 'n Ander verklaring kan wees dat nie al die pasiënte dit dalk kon gelees en verstaan het nie. Alhoewel dit aanbeveel word dat die fetale bewegingskaart aan alle pasiente vanaf 28 weke swangerskapsduur gegee word, het die pasiente dit eers vanaf 30 weke swangerskapsduur ontvang, wat 'n moontlike verkJaring kan wees waarom so min pasiënte van die korrekte aantal fetale bewegings geweet het. Agt respondente was ten tye van die onderhoud tussen 29-32 weke swanger.

\section{AANBEVELINGS}

Die navorser is van mening dat dit noodsaaklik is om indringend na gesondheidsvoorligting binne die hospitaal te kyk. Alhoewel die waarde van op-die-plek onderrig glad nie misken word nie, is die langtermynvoordele wat gesondheidsvoorligting inhou so belangrik, dat voorligting nie maar net lukraak en toevallig kan plaasvind nie. Die gesondheidsdiensverbruiker moet voortdurend blootgestel word aan voorligting wat ingestel is op hulle behoeftes, wat op die regtc tydstip tydens swangerskap aangebied word en wat deur goed opgeleide personeel voorsien word.

Dit is belangrik dat gesondheidsvoorligtingsvaardighede voortdurend gečvalueer sal word. Klem moet gelê word op die inhoud sowel as die manier waarop dit oorgedra word. Dit beteken ook dat die verpleegkundige bewus moet wees van die waardes en norme van die groep vir wie sy voorligting gee.

Die moontlikheid van geïndividualiseerde selfstudiepakette waarin die nodige geleentheid geskep word vir die uitbreiding en inoefening van gesondheidsvoorligtingsvaardighede, moet ondersock word. Volgens die navorser behoort elke verpleegkundige van tyd tot tyd bewys te kan lewer van sodanige programme wat suksesvol voltooi is.

Ondersoek behoort gedoen te word na rekordhouding van gesondheidsvoorligting wat gegee is. Die moontlikheid bestaan dat kontrolelyste aan die pasiënt se voorgeboortekaart aangeheg word waarop die voorligting wat gegee is kernagtig aangedui kan word. Met die volgende besoek kan dan vlugtig geềvalueer word wat die pasiènt se kennis daaromtrent is. Leemtes in die pasiënt se kennis kan sodoende opgespoor word sonder om elke keer inligting wat vir die pasient bekend is, bloot te hierhaal nie.

\section{SLOT}

In hierdie artikel is gepoog om enkele aspekte rakende gesondheid en die swanger vrou van aan te raak. Heelwat probleme ten opsigte van gesondheidsvoorligting aan swanger vroue is geidentifiseer en voorstelle is gemaak om die probleem decls aan te spreek.

\section{BRONNELYS}

Boeke en Tydskrifte: Whose Responsibility Is it and Who Should
CHAISOON, G.M. 1979: Patient Education: be doing it? Nursing Administration Quarterly, 4:1-11.

CONWAY-RUTKOWSKI, B. (Guest-Ed). 1982: Patient Compliance. The Nursing Clinics of North-America, 17(3): 449-466.

DOWSETT, S.J. 1985: Smoking attitudes and habits during pregnancy, Sheffield 1983. Health Education Journal, 44(2): 83-86

EGGERTSEN, S.C. AND BENEDETTI, TJ. 1987: Maternal response to Daily Fetal Movement Counting in Primary Care Settings. American Journal of Perinatology, 4(4): $327-330$.

EISER, C. AND EISER, J.R. 1985: Health education needs of primigravidae. Child: Care, Health and Development, 11(2): 53-60.

FERRANS, C.E., POWERS, M.J. AND KASCH,C.R. 1987: Satisfaction with heal th care of Hemodialysis patients. Research in Nursing and Health. 10(6): 367-374.

HAVING A BABY IN EUROPE. 1985: Public Health in Europe 26. Denmark: World Health Organization.

MACARTHUR, C., NEWTON, J.R. AND KNOX, E.G. 1987: Effect of anti-smoking health education on infant size at birth: a randomized controlled trial. British Journal of Obstetrics and Gynaecology, 94:295-300.

TILLEY, J.D., GREGOR, F.M. AND THIESSEN, V. 1987: The nurse's role in patient education: incongruent perceptions among nurses and patients. Journal of Advanced Nursing, 19: 291-301.

WILES, L.S. 1984: The effect of Prenatal Breastfeeding Education on Breastfeeding Success and Maternal Perception of the Infant. Joumal of Obstetric, Gynecologic and Neonatal Nursing, July - August: 253-257.

\section{Ongepubliseende Werke:}

BESTER, M.E. 1989: Die benutting van voorgeboortesorgdienste deur hoërisikoprimigravidas van die Tygerberghospitaal. Magisterverhandeling in Verpleegkunde Universiteit van Stellenbosch.

\begin{tabular}{c} 
ME. Bester \\
Universiteit van Siellenbosch \\
\hline
\end{tabular}

